\title{
Effects of Multidisciplinary Participatory Design Method on Students' Engineering Design Process
}

\author{
Yu-Hung Chien *(D), Chun-Kai Yao and Yu-Han Chao \\ Department of Technology Application and Human Resource Development, National Taiwan Normal \\ University, Taipei 106, Taiwan; k2585258@gmail.com (C.-K.Y.); littletia.chao@gmail.com (Y.-H.C.) \\ * Correspondence: roland.chien@ntnu.edu.tw
}

Received: 29 August 2020; Accepted: 8 October 2020; Published: 10 October 2020

\begin{abstract}
This study took the ergonomics design course as an example to propose a design teaching model of multidisciplinary participatory design (MPD), and investigated the effects of this teaching model on the engineering design behavior of college students. We used lag behavior sequential analysis to compare the design behaviors of three student groups: a participatory design (PD) experimental group, an MPD experimental group, and a control group. The results of the study show that (1) students in the PD experimental group had 13 significant sequential engineering design behaviors, students in the MPD experimental group had 10, and students in the control group had only seven. The engineering design behaviors of the experimental groups were more diversified than those of the control group. (2) The three groups of students had a small number of significant design behavior transfers in the engineering design process, indicating that the students' sequential design behaviors between two different design activities were insufficient. We concluded by detailing the pros and cons of using the MPD teaching model based on the results of this study, and hopefully by providing a reference for teaching engineering design.
\end{abstract}

Keywords: engineering design behavior; multidisciplinary; participatory design

\section{Introduction}

Engineering design teaching pays special attention to students' cognitive structures related to the design process $[1,2]$. The design process cannot be taught only by lecturing, but also requires more teaching strategies [3]. Currently, most design teaching processes adopt project-based learning, allowing students to implement designs based on actual design issues. Learning by doing allows students to accumulate relevant design knowledge, technology and experience [4].

According to the above, at the core of a design course, which is of the utmost importance, is enabling students to acquire all of the necessary key abilities for completing the design process and achieving innovative design results [5]. However, students often ignore the importance of iterations (i.e., repeating the same deign behavior continuously) and transfers (i.e., sequential design behaviors from one to the other), skipping design processes such as re-design, feasibility and communication. Therefore, students' concepts of these processes are vague [6]. Some of the usual problems involved in design include the challenging, poorly structured, complex and difficult to define requirements [7], and users may have different perceptions and attitudes toward the same design issue. Therefore, only by understanding design issues and users from different perspectives, repeatedly diagnosing design problems with stakeholders in the design process, and constantly modifying the design can students reach the end of the design process [8]. Consequently, how teachers improve students' understanding and practice of the design process is of great importance [9].

Design courses can be divided into two categories, namely, the capstone course and the cornerstone course [10]. Most design courses first enlighten students with basic cornerstone courses 
(including courses providing declarative and procedural knowledge) [11], and then implement capstone project-based learning courses. All design departments have capstone project-based learning courses every semester to train students in the engineering design process using the knowledge and skills they have learned. However, as mentioned earlier, with the advancement of technology, design issues have become diverse and complex, and students often lack experience in observation, interviews, knowledge in design theory, and practical experience in engineering design activities [12]. They need the assistance of more roles to understand users in depth, and to guide them to evaluate design issues. In other words, design education requires the cooperation of different professions to help students understand the needs of users, to conduct in-depth research on different knowledge issues, and then to determine which issues are at the core and which issues need to be further studied.

In view of the abovementioned design teaching issues, this study found that participatory design (PD) emphasizes cooperation among users, stakeholders and designers so as to deeply participate in the design process [13], as well as multidisciplinary collaboration. The use of collaborative learning could be combined into a "multidisciplinary participatory design (MPD)" [8], which could become a different teaching strategy for strengthening students' understanding and practice of the engineering design process, thereby stimulating creativity [14].

\subsection{Multidisciplinary Approach in Design Education}

Design is a profession that requires the integration of humanities, art, technology, engineering, and other related sciences, aesthetics, materials, mechanics and physics [15]. However, it is impossible for designers to know in-depth all the fields; this requires multi-domain experts to work together to achieve a balance among user needs, product production, application feasibility and product sustainability [16]. Therefore, design education should focus on communication and cooperation with experts in multiple fields in order to help students construct ways to apply cross-domain knowledge to generate creative ideas [17], as these abilities will affect the future employment of students [18]. However, in a multi-domain team, the professional backgrounds of the team members are not the same and the "professional language" used is quite different. Therefore, the way in which to develop the cognition of students in various fields has become key to the success of multidisciplinary design courses $[8,19]$, and this study aimed to investigate it further.

\subsection{Participatory Design}

PD originated in Scandinavia between 1970 and 1980. The development of production automation forced people to believe that automated processes would replace existing labor and cause a lot of unemployment. Others believed that the purpose of automation was not to replace labor with machinery, but to treat laborers as experts in the production and use of machines. Through communication between labor and management, the production process and working environment were improved, and a democratic political relationship in the workplace was obtained [20]. PD regards users as experts, and thus the overall design solutions improve with user participation [13]. PD allows product users a certain degree of leadership in the design process, and grants them the right to control the final product [21]. Product users play an important role in the design process, as they provide user experiences and diverse views essential to design [22]. Therefore, if users can participate in all stages of the design process, they will be promoted from the role of information providers to co-designers. Consequently, using PD when teaching might promote the transfer of students' design behaviors into design practices similar to those of expert designers.

Altogether, the purpose of this study was to examine the effects of PD and multidisciplinary collaboration on students' engineering design processes. Through experimental teaching, we investigated the ability of the teaching model to enhance students' ability to apply knowledge to design and their cognitive structure of the overall design process. As such, the research questions of this study were as follows: 
1. Is there any difference in the overall engineering design behavior frequency distribution of different collaboration student groups?

2. Is there any difference in the sequential diagram of students' engineering design behaviors of different collaboration student groups?

\section{Experimental Section}

To answer the questions listed above, an ergonomics design course was used to implement the experimental teaching. Students were grouped into three different combinations (i.e., PD experimental group, MPD experimental group, and control group). All members of the student teams worked together through the entire course and were asked to participate in a design workshop in the last week of the course, which focused on designing portable self-defense whistles for women. The dialogues of the team members were recorded during the design workshop, and the behavioral sequence analysis method [23] was used to examine the differences among the engineering design behavior sequences of the three groups of students.

\subsection{Participants and Course}

In total, 25 third-year university students participated in this study. Students freely united into groups with 3-4 students, resulting in the following: (1) a PD experimental group (some students were target users, i.e., female students, and they were from the same discipline) with three teams and 12 students; (2) an MPD experimental group (some students were the target users and they were from different disciplines), with two teams and nine students, and the composition of the students included the Department of Science and Technology, the Department of Graphic Communication, the Department of East-Asian Study, and the Department of Earth Sciences; (3) a control group (students were not the target users and they were from the same discipline), with one team and four students.

At the core of a design course, which is of the utmost importance, is enabling students to acquire all of the necessary key abilities to practice the complete design process and to achieve innovative design results [5]. This study took the ergonomics course as an example because (1) ergonomics knowledge is widely used, so students from different disciplines often elect this course, and (2) this course combines knowledge teaching, research and a design project, so that students can experience the process of practical design through learning knowledge and skills.

The entire course lasted 18 weeks, broken down into $3 \mathrm{~h}$ a week, i.e., $54 \mathrm{~h}$ in total. The course can be divided into three phases. The first phase (weeks 1-9) involved lecturing. In the first week of the course, students formed teams for team-building purposes at the very beginning of the course. In the subsequent 8 weeks, the student teams were asked to discuss questions related to the chapters of the ergonomics textbook, then the teacher explained the content of the chapter, and together, the teacher and the students discussed the answers to the questions. Finally, online interactive quiz games were conducted. The second phase (weeks 10-17) involved ergonomic research. The student teams conducted studies related to the topics learned from previous chapters, and then discussed their studies with teachers and presented their progress in class. The third phase (week 18) encompassed a design workshop, and in this case, the topic was the portable self-defensive whistle design.

\subsection{Design and Procedure}

In the 18th week of the course, the student teams were asked to cooperate to design a portable self-defense whistle for females to use in daily life. The teacher of the course started by giving the students a $30 \mathrm{~min}$ brief to introduce the principle of sound for a whistle, the relevant products on the market, and the occasion of product use. After the brief, the student teams started the engineering design process by generating design solutions for $90 \mathrm{~min}$. Each student team used mobile phones to record the entire dialogue of the team members in the design process. All of the student teams drew their ideas on A4-sized paper and then scanned their drawings using their mobile phones. Finally, 
the audio recording files and the digital drawing files were uploaded to the course's Moodle system before the design workshop was finished.

\subsection{Analysis Method}

All of recorded audio dialogues of the student teams were compiled and coded via coding items based on the engineering design process proposed in previous studies [9]. The code items are shown in Table 1. Two authors completed the coding of the student teams' dialogues separately, and the interrater Kappa reliability coefficient was $0.938(p<0.001)$, showing high consistency.

Table 1. Codes of the engineering design behavior [9].

\begin{tabular}{ccc}
\hline Code & Design Activity & Description \\
\hline IN & Identifying needs & Identifying basic needs. \\
DP & Defining problem & Defining what the problem really is. \\
GA & Gathering information & Collecting information needed to solve the problem. \\
GI & Generating ideas & Thinking up potential solutions to the problem. \\
MO & Modeling & Detailing how to build a solution to the problem. \\
FA & Feasibility analysis & Assessing and passing judgment on a possible or planned solution to the problem. \\
EV & Evaluation & Comparing and contrasting solutions to the problem on a particular dimension. \\
DE & Decisions & Selecting a solution to the problem. \\
CO & Communication & Communicating elements of the design in writing or with oral reports to parties such \\
NO & None & as contractors and the community. \\
\hline
\end{tabular}

According to the coded results, the frequency and ratio distribution of the engineering design behaviors were analyzed. Then, lag sequential analysis was conducted [23] and the continuous significance of each sequence in the engineering design process was found. Finally, a sequential diagram was drawn to explore the cognitive patterns of these engineering design behaviors.

\section{Results}

First of all, there were three teams of students in the PD experimental group. The audio recording files collected 39,894 words, i.e., 2398 dialogues with 1752 design behaviors and 646 non-design behaviors. The MPD experimental group had two teams, and 21,213 words were collected, i.e., 2292 dialogues with 1829 design behaviors and 463 non-design behaviors. Finally, the control group included only one team of students, and a total of 14,697 words were collected, i.e., 848 dialogues with 745 design behaviors and 103 non-design behaviors. In total, 75,804 words were collected, including 5538 dialogues with 4326 design behaviors and 1212 non-design behaviors. The frequency percentages of the engineering design behaviors are shown in Figure 1 and Table 2.

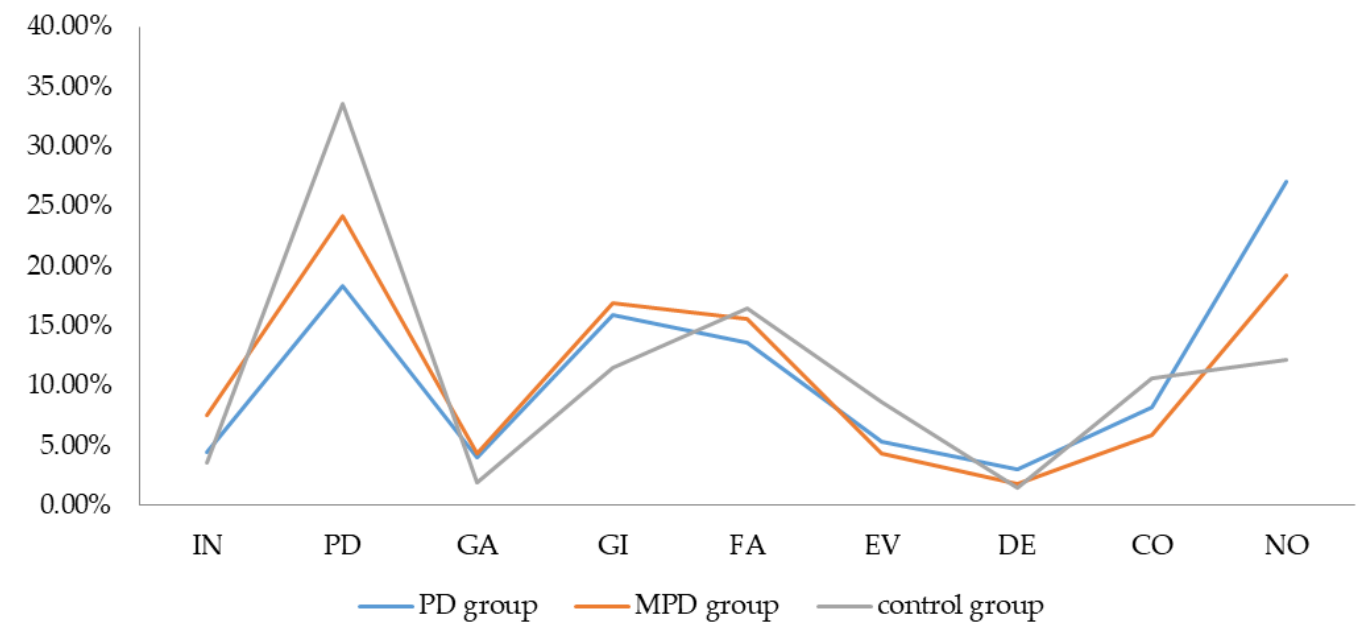

Figure 1. A comparison of the design behavior frequencies of different student groups. 
Table 2. The detailed percentages (\%) of the design behavior frequency of the student groups.

\begin{tabular}{|c|c|c|c|c|c|c|c|c|c|}
\hline Groups & $\begin{array}{l}\text { Identifying } \\
\text { Needs } \\
\text { (IN) }\end{array}$ & $\begin{array}{l}\text { Defining } \\
\text { Problem } \\
\text { (DP) }\end{array}$ & $\begin{array}{l}\text { Gathering } \\
\text { Information } \\
\text { (GA) }\end{array}$ & $\begin{array}{c}\text { Generating } \\
\text { Ideas } \\
\text { (GI) }\end{array}$ & $\begin{array}{c}\text { Feasibility } \\
\text { Analysis } \\
\text { (FA) }\end{array}$ & $\begin{array}{l}\text { Evaluation } \\
\text { (EV) }\end{array}$ & $\begin{array}{l}\text { Decisions } \\
\text { (DE) }\end{array}$ & $\begin{array}{l}\text { Communication } \\
\text { (CO) }\end{array}$ & $\begin{array}{l}\text { None } \\
\text { (NO) }\end{array}$ \\
\hline PD group & 4.43 & 18.34 & 3.99 & 15.98 & 13.60 & 5.33 & 3.04 & 8.17 & 27.12 \\
\hline Team1 & 5.64 & 27.92 & 4.02 & 11.09 & 12.81 & 5.93 & 2.29 & 6.69 & 23.61 \\
\hline Team 2 & 4.25 & 14.80 & 5.61 & 20.75 & 16.33 & 6.12 & 2.38 & 5.78 & 23.98 \\
\hline Team 3 & 3.40 & 12.30 & 2.36 & 16.10 & 11.65 & 3.93 & 4.45 & 12.04 & 33.77 \\
\hline MPD group & 7.57 & 24.18 & 4.39 & 16.90 & 15.65 & 4.35 & 1.82 & 5.87 & 19.26 \\
\hline Team 1 & 7.68 & 15.86 & 6.19 & 19.35 & 16.86 & 5.55 & 2.63 & 2.49 & 23.40 \\
\hline Team 2 & 7.45 & 32.51 & 2.60 & 15.45 & 14.45 & 3.16 & 1.02 & 9.26 & 15.12 \\
\hline Control group & 3.54 & 33.61 & 1.89 & 11.56 & 16.51 & 8.61 & 1.53 & 10.61 & 12.15 \\
\hline
\end{tabular}




\subsection{PD Experimental Group}

Table 3 shows the proportion of the students' design behaviors in the PD experimental group. The students showed frequent design behaviors in the categories of defining the problem (DP) $(19.73 \%)$, generating ideas (GI) $(15.06 \%)$, feasibility analysis (FA) $(13.31 \%)$ and none (NO) $(26.91 \%)$, accounting for approximately $75.01 \%$ of the total design behaviors.

Table 3. The frequency percentages (\%) of the design behaviors of the students in the PD experimental group.

\begin{tabular}{cccccccccc}
\hline Codes & IN & DP & GA & GI & FA & EV & DE & CO & NO \\
\hline IN & 26.36 & 20.00 & 0.91 & 17.27 & 10.91 & 1.82 & 2.73 & 1.82 & 18.18 \\
DP & 4.65 & 36.36 & 3.59 & 18.18 & 14.59 & 6.13 & 0.85 & 3.59 & 12.05 \\
GA & 8.60 & 17.20 & 22.58 & 15.05 & 10.75 & 6.45 & 0.00 & 2.15 & 17.20 \\
GI & 1.66 & 19.11 & 3.32 & 27.70 & 16.90 & 5.26 & 3.60 & 2.77 & 19.67 \\
FA & 1.88 & 22.88 & 4.08 & 15.05 & 29.47 & 8.15 & 2.82 & 1.57 & 14.11 \\
EV & 7.03 & 15.63 & 3.13 & 13.28 & 18.75 & 10.94 & 10.94 & 3.91 & 16.41 \\
DE & 6.94 & 15.28 & 1.39 & 11.11 & 8.33 & 5.56 & 20.83 & 16.67 & 13.89 \\
CO & 2.04 & 10.20 & 2.04 & 10.20 & 2.55 & 1.53 & 2.55 & 41.33 & 27.55 \\
NO & 3.26 & 10.85 & 3.10 & 7.60 & 5.89 & 3.88 & 1.40 & 9.61 & 54.42 \\
\hline Total & 4.59 & 19.73 & 3.88 & 15.06 & 13.31 & 5.34 & 3.00 & 8.18 & 26.91 \\
\hline
\end{tabular}

Figure 2 shows a sequential diagram of the students' engineering design behaviors. As shown, 13 significant behavior sequences existed in the PD experimental group, which included eight self-iterations, namely, identifying needs $((\mathrm{IN}) \rightarrow \mathrm{IN}, \mathrm{DP} \rightarrow \mathrm{DP})$, gathering information $((\mathrm{GA}) \rightarrow \mathrm{GA}$, $\mathrm{GI} \rightarrow \mathrm{GI}, \mathrm{FA} \rightarrow \mathrm{FA})$, evaluation $((\mathrm{EV}) \rightarrow \mathrm{EV})$, decisions $((\mathrm{DE}) \rightarrow \mathrm{DE})$, communication $((\mathrm{CO}) \rightarrow \mathrm{CO})$, and five sequential behavior transfers from $\mathrm{DP} \rightarrow \mathrm{GI}, \mathrm{GI} \rightarrow \mathrm{FA}, \mathrm{FA} \rightarrow \mathrm{EV}, \mathrm{EV} \rightarrow \mathrm{DE}$, and $\mathrm{DE} \rightarrow \mathrm{CO}$. A sequential behavior transfer from $\mathrm{GA} \rightarrow \mathrm{DE}$ was absent.

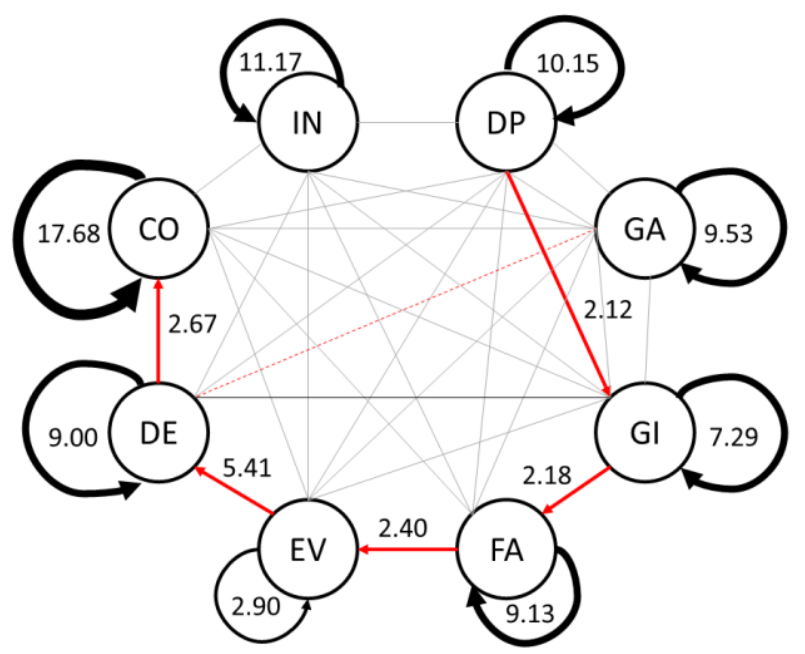

Figure 2. A sequential diagram of the students' design behaviors in the PD experimental group.

\subsection{MPD Experimental Group}

Table 4 shows the proportions of the design behavior sequences of the students in the MPD experimental group, finding that the students had frequent design behaviors in DP (22.30\%), GI (17.46\%), FA $(15.93 \%)$ and NO $(20.17 \%)$, accounting for approximately $75.86 \%$ of the total design behaviors.

Figure 3 shows a sequential diagram of the students' engineering design behaviors. As shown, 10 significant behavior sequences existed in the MPD experimental group-eight iterations, namely, $\mathrm{IN} \rightarrow \mathrm{IN}, \mathrm{DP} \rightarrow \mathrm{DP}, \mathrm{GA} \rightarrow \mathrm{GA}, \mathrm{GI} \rightarrow \mathrm{GI}, \mathrm{FA} \rightarrow \mathrm{FA}, \mathrm{EV} \rightarrow \mathrm{EV}, \mathrm{DE} \rightarrow \mathrm{DE}$ and $\mathrm{CO} \rightarrow \mathrm{CO}$, and two sequential 
behavior transfers from $\mathrm{GA} \rightarrow \mathrm{IN}$ and $\mathrm{EV} \rightarrow \mathrm{DE}$. A sequential behavioral transfer from $\mathrm{GA} \rightarrow \mathrm{DE}$ was absent.

Table 4. The frequency percentages (\%) of the design behaviors of the students in the MPD experimental group.

\begin{tabular}{cccccccccc}
\hline Codes & IN & DP & GA & GI & FA & EV & DE & CO & NO \\
\hline IN & 27.59 & 21.84 & 7.47 & 15.52 & 6.90 & 1.15 & 1.15 & 2.30 & 16.09 \\
DP & 5.09 & 39.53 & 3.13 & 15.66 & 12.33 & 3.91 & 0.98 & 3.91 & 15.46 \\
GA & 17.27 & 20.00 & 26.36 & 6.36 & 10.00 & 3.64 & 0.00 & 0.91 & 15.45 \\
GI & 2.75 & 19.00 & 2.75 & 31.50 & 18.75 & 5.50 & 1.25 & 2.50 & 16.00 \\
FA & 4.93 & 14.25 & 3.01 & 16.44 & 35.07 & 4.38 & 3.01 & 2.47 & 16.44 \\
EV & 5.66 & 16.98 & 2.83 & 12.26 & 13.21 & 20.75 & 8.49 & 1.89 & 17.92 \\
DE & 4.35 & 26.09 & 4.35 & 23.91 & 4.35 & 2.17 & 15.22 & 2.17 & 17.39 \\
CO & 9.40 & 21.37 & 3.42 & 8.55 & 4.27 & 0.85 & 0.85 & 32.48 & 18.80 \\
NO & 7.14 & 14.29 & 4.55 & 14.29 & 11.90 & 3.90 & 1.30 & 6.93 & 35.71 \\
\hline Total & 7.59 & 22.30 & 4.80 & 17.46 & 15.93 & 4.63 & 2.01 & 5.11 & 20.17 \\
\hline
\end{tabular}

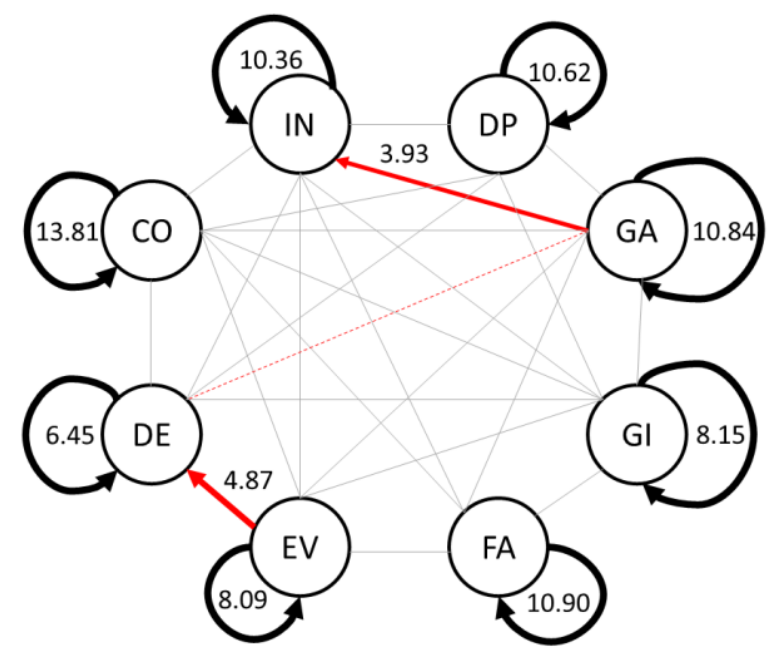

Figure 3. A sequential diagram of the students' design behaviors in the MPD experimental group.

\subsection{Control Group}

Table 5 shows the proportions of the design behavior sequences of the students in the control group. The students had frequent design behaviors in DP (33.65\%), GI (11.57\%), FA (16.53\%) and NO $(12.04 \%)$, accounting for approximately $73.79 \%$ of the total design behaviors.

Table 5. The frequency percentages (\%) of the design behaviors of the students in the control group.

\begin{tabular}{cccccccccc}
\hline Codes & IN & DP & GA & GI & FA & EV & DE & CO & NO \\
\hline IN & 26.67 & 33.33 & 0.00 & 3.33 & 16.67 & 3.33 & 3.33 & 0.00 & 13.33 \\
DP & 1.75 & 49.47 & 1.05 & 12.98 & 10.53 & 5.26 & 0.35 & 6.67 & 11.93 \\
GA & 0.00 & 31.25 & 6.25 & 18.75 & 6.25 & 6.25 & 0.00 & 12.50 & 18.75 \\
GI & 2.04 & 21.43 & 3.06 & 13.27 & 26.53 & 11.22 & 1.02 & 8.16 & 13.27 \\
FA & 2.14 & 28.57 & 2.14 & 13.57 & 27.14 & 8.57 & 2.86 & 8.57 & 6.43 \\
EV & 2.74 & 28.77 & 2.74 & 8.22 & 19.18 & 20.55 & 2.74 & 6.85 & 8.22 \\
DE & 0.00 & 38.46 & 0.00 & 7.69 & 15.38 & 15.38 & 15.38 & 0.00 & 7.69 \\
CO & 3.37 & 15.73 & 1.12 & 10.11 & 5.62 & 11.24 & 1.12 & 44.94 & 6.74 \\
NO & 6.80 & 27.18 & 2.91 & 8.74 & 18.45 & 5.83 & 0.97 & 3.88 & 25.24 \\
\hline Total & 3.54 & 33.65 & 1.89 & 11.57 & 16.53 & 8.62 & 1.53 & 10.63 & 12.04 \\
\hline
\end{tabular}


Figure 4 shows a sequential diagram of the students' engineering design behaviors. As shown, six significant sequential behaviors existed in the control group. The significant sequences were the seven iterations of $\mathrm{IN} \rightarrow \mathrm{IN}, \mathrm{DP} \rightarrow \mathrm{DP}, \mathrm{FA} \rightarrow \mathrm{FA}, \mathrm{EV} \rightarrow \mathrm{EV}, \mathrm{DE} \rightarrow \mathrm{DE}$ and $\mathrm{CO} \rightarrow \mathrm{CO}$, and only one transfer from GI $\rightarrow$ FA. The seven sequential behavioral transfers from $\mathrm{IN} \rightarrow \mathrm{DE}, \mathrm{IN} \rightarrow \mathrm{CO}, \mathrm{GA} \rightarrow \mathrm{IN}, \mathrm{GA} \rightarrow \mathrm{DE}$, $\mathrm{DE} \rightarrow \mathrm{IN}, \mathrm{DE} \rightarrow \mathrm{GA}$ and $\mathrm{DE} \rightarrow \mathrm{CO}$ were absent.



Figure 4. A sequential diagram of the students' design behaviors in the control group.

\section{Discussion}

The overall engineering design behavior frequency distributions of the three student groups were similar (Figure 1). The design behaviors were mostly concentrated on the same design activities of DP, GI and FA. That is, the design activities of the three student groups were more active in defining design problems, generating problem solutions, and discussing the feasibility of their solutions, but less active in identifying needs (IN), gathering information (GA), evaluation (EV), decisions (DE) and communication (CO). However, these results only show the distributions of the students' design activities at each design stage, and not the transfer relationship between said behaviors. Therefore, based on the results of the behavior sequence analysis, a further design behavior transfer comparison of the three student groups was made.

At the core of the engineering design activities is iteration and transfer $[6,9,24]$, which form the basis and manifestation of the complete engineering design process [24]. Therefore, we used lag behavior sequence analysis to investigate the engineering design behavior sequences of the students, and found that although the distributions of students' engineering behaviors were similar, the sequential engineering behaviors among the three different student groups were quite different. After comparing the design behavior patterns of the three student groups, it was found that the students in the PD experimental group had 13 significant engineering design behavior sequences, whereas students in the MPD experimental group had 10, and the control group only had 7 . This indicates that students in the PD and MPD experimental groups with users involved in the design process had more significant design behaviors compared to those in the control group. Moreover, both the PD and the MPD experimental groups included a significant iterative process in all eight design activities, i.e., each design behavior was self-repeated multiple times. The control group students' self-repetitive behaviors in GA and GI were not significant, which may give rise to insufficient design-related information and a lack of understanding of product users, which could lead to an inability to truly analyze the feasibility of the design concept or to determine the final design program. In addition, the results show that the PD experimental group had five behavior transfers between different design activities, whereas the MPD experimental group had two and the control group only had one. User participation in design activities can promote the transfer of students' design behaviors in the process of engineering design, 
and their ability to carry out more complete design activities. On the other hand, although the MPD experimental group had a more complete process of performing engineering design activities than the control group did, it was not better than that of the PD experimental group. Previous studies suggest that multi-domain team members' understanding of design contributions affects the performance of multi-domain cooperation [25]. However, the multidisciplinary effect was only slightly related to students' design behaviors in the present study.

Among the eight engineering design activities, there should be 64 sequential design behaviors (eight iterations and 56 transfers) to reach a complete design process. Although there were not many significant sequential design behaviors in the three student groups, most design behavior sequences occurred, and only a few sequential design behaviors did not occur completely. In the PD and MPD experimental groups, only the design behavior transfer from GA to DE was absent, while six design behavior transfers in the control group did not occur. Therefore, the experimental groups promoted more complete design activities than the control group did.

It is worth mentioning that the three student groups had similar non-engineering design behaviors (i.e., the group members chatted or digressed frequently). Previous studies indicate that discussion and social conversations related to the topic are mostly intertwined. This kind of social conversation can promote group identity [26], but generally speaking, if the group discusses outside the topic frequently, it has a negative impact on the quality of the design process.

\section{Conclusions and Future Study}

Based on the above discussion, the conclusions of this study are as follows.

Design teaching often takes students' design works as the basis for evaluating learning effectiveness, but learning to implement a complete design procedure is an important basis for design teaching. This study suggests that only evaluating the students' design works ignores the integrity of the students' engineering design process. Thus, we recommend a deeper focus on the evaluation of design process learning.

Sequential design behaviors, including iterations and transfers, are an important basis for design activities in terms of obtaining better design results [9]. In evaluating learning engineering design, we should not only pay attention to the proportion of various design activities being implemented, but also focus on the iterative behaviors between the same design activity and the transfer between different design activities. This ensures that students generate a complete design process to reach better design outcomes.

The results of this study show that user participation in the design process can promote a more complete design behavior. In contrast, the impact of multidisciplinary cooperation on engineering design activities was small in this study, and the reasons for this need to be elucidated in further studies.

This study recorded the design behavior of student groups in the form of a two-hour workshop. Based on the results, a long-term longitudinal study on engineering behavior might be needed in the future.

Author Contributions: Conceptualization, design, methodology, interpretation, critical revision of the manuscript, and final approval of the manuscript, Y.-H.C. (Yu-Hung Chien); data collection and formal analysis, C.-K.Y.; writing-original draft preparation, Y.-H.C. (Yu-Han Chao). All authors read and agreed to the published version of the manuscript.

Funding: This research was funded by the Ministry of Science and Technology, Taiwan (grant number MOST 107-2511-H-003-047-MY3) and the Ministry of Education, Taiwan (grant number PHA1080053).

Conflicts of Interest: The authors declare no conflict of interest.

\section{References}

1. Mills, J.E.; Treagust, D.F. Engineering education-Is problem-based or project-based learning the answer. Australas. J. Eng. Educ. 2003, 3, 2-16. 
2. Chien, Y.H.; Hsiao, H.S.; Chang, Y.S.; Lin, K.Y. Engaging students in using 3D printing technology to enhance cognitive structures and thought processes relevant to engineering design. J. Eng. Sci. Technol. 2018, 13, 27-34.

3. Dym, C.L.; Agogino, A.M.; Eris, O.; Frey, D.D.; Leifer, L.J. Engineering design thinking, teaching, and learning. J. Eng. Educ. 2005, 94, 103-120. [CrossRef]

4. Uluoğlu, B. Design knowledge communicated in studio critiques. Des. Stud. 2000, 21, 33-58. [CrossRef]

5. Khot, S.B.; Jadhav, P.J.; Jadhav, P.M. Teaching engineering design module from engineering exploration and design project (EEDP) course through hands on activities. J. Eng. Educ. Transform. 2020, 33, 524-527.

6. Mesutoglu, C.; Baran, E. Examining the development of middle school science teachers' understanding of engineering design process. Int. J. Sci. Math. Educ. 2020, 1-21. [CrossRef]

7. Buchanan, R. Wicked problems in design thinking. Des. Issues 1992, 8, 5-21. [CrossRef]

8. McIntosh, J.; Marques, B. Designing for culturally-diverse communities. The role of collaborative, interdisciplinary design-led research. J. Public Space 2017, 2, 21-30. [CrossRef]

9. Atman, C.J.; Adams, R.S.; Cardella, M.E.; Turns, J.; Mosborg, S.; Saleem, J. Engineering design processes: A comparison of students and expert practitioners. J. Eng. Educ. 2007, 96, 359-379. [CrossRef]

10. Little, P.; King, J. Selection criteria for cornerstone and capstone design projects. Int. J. Eng. Educ. 2001, 17, 406-409.

11. Goldschmidt, G. Expert knowledge or creative spark? Predicaments in design education. In Expert in Design, Design Thinking Research Symposium; University of Technology: Sydney, Australia, 2003.

12. Norman, D. Why Design Education Must Change. Available online: https://goo.gl/vE4SFE (accessed on 26 August 2020).

13. Sanders, E.B.N.; Stappers, P.J. Probes, toolkits and prototypes: Three approaches to making in codesigning. Codesign 2004, 10, 5-14. [CrossRef]

14. Joachim, S.; Petra, B.S. Thinking in design teams-An analysis of team communication. Des. Stud. 2004, 23, 473-496.

15. Chien, Y.H.; Chu, P.Y. The different learning outcomes of high school and college students on a 3d-printing STEAM engineering design curriculum. Int. J. Sci. Math. Educ. 2018, 16, 1047-1064. [CrossRef]

16. Brown, T. Strategy by design. Fast Co. 2005, 95, 52-54.

17. Chen, W.Z.; Yu, W.L. The problems and implications of online collaborative design learning projects. Res. Arts Educ. 2008, 15, 105-135.

18. Cross, N. Engineering Design Method: Strategy for Product Design; John Wiley \& Sons Ltd.: Chichester, UK, 2000.

19. Tang, H.H.; Lin, Y.Q. The influence and problems of scenario design approach on multi-disciplinary collaboration design. J. Des. 2011, 16, 21-44.

20. Schuler, D.; Namioka, A. Participatory Design: Principles and Practices; Lawrence Erlbaum Associates: New York, NY, USA, 1993.

21. Kang, M.; Choo, P.; Watters, C.E. Design for experiencing: Participatory design approach with multidisciplinary perspectives. Procedia Soc. Behav. Sci. 2015, 174, 830-833. [CrossRef]

22. Björgvinsson, E.; Ehn, P.; Hillgren, P.A. Agonistic participatory design: Working with marginalised social movements. Codesign 2020, 8, 127-144. [CrossRef]

23. Bakeman, R.; Gottman, J.M. Observing Interaction: An Introduction to Sequential Analysis; Cambridge University Press: Cambridge, UK, 1997.

24. Adams, R.; Atman, C. Characterizing engineering student design processes: An illustration of iteration. Am. Soc. Eng. Educ. 2000, 1-11. [CrossRef]

25. Richter, D.; Paretti, M. Identifying barriers to and outcomes of interdisciplinarity in the engineering classroom. Eur. J. Eng. Educ. 2009, 34, 29-45. [CrossRef]

26. Wu, S.Y.; Hou, H.T.; Hwang, W.Y. Exploring students' cognitive dimensions and behavioral patterns during a synchronous peer assessment discussion activity using instant messaging. Asia Pac. Educ. Res. 2012, $21,442-453$.

(C) 2020 by the authors. Licensee MDPI, Basel, Switzerland. This article is an open access article distributed under the terms and conditions of the Creative Commons Attribution (CC BY) license (http://creativecommons.org/licenses/by/4.0/). 